\title{
Acolhimento Precoce e o Vínculo na Institucionalização
}

\author{
Gabriela Golin \\ Silvia Pereira da Cruz Benetti \\ Universidade do Vale do Rio dos Sinos
}

\begin{abstract}
RESUMO - Este artigo propõe a análise das demandas psicológicas de três meninos, com idades entre 1 e 2 anos, abrigados em uma instituição localizada no estado do Rio Grande do Sul. Para a coleta dos dados, aplicou-se aos cuidadores principais uma entrevista de transtorno do apego. Após, realizaram-se observações dos meninos e de seus cuidadores por meio de uma inspiração do Método Bick de Observação. Também foram acessados os dados disponíveis das suas histórias de vida e realizada uma entrevista não estruturada com esses profissionais, responsáveis pelas crianças. Concluiu-se que, em virtude da busca ativa dessas crianças pelos cuidadores, faz-se necessário o seu amparo emocional constante, visando o estabelecimento de interações privilegiadas e sensíveis, a partir da interação com seus cuidadores.
\end{abstract}

Palavras-chave: acolhimento precoce, crianças abrigadas, interação, vínculo

\section{Early Sheltering and Bonding in Institution}

\begin{abstract}
This article proposes the comprehension and analysis of the psychological demands of three boys with ages between one and two years sheltered in an institution at Rio Grande do Sul, Brazil. In order to collect the data, an interview was conducted with the caretakers to evaluate an attachment disorder. Afterwards, the boys were observed through an adaptation of the Bick's Method of Observation. It was concluded that, the active pursuit of those children towards their caretakers indicated the need of a constant emotional support to them in order to establish sensitive and privileged interaction with caretakers. This way the results point out to the urgency of specific support work for the caretakers in order to provide a proper care of the children sheltered prematurely.
\end{abstract}

Key words: premature shelter, sheltered children, interaction, bonding

O vínculo mãe-bebê constitui a base emocional do indivíduo (Bowlby, 1969/2002; Winnicott, 1965/2001). Conforme Ainsworth (1982), esse vínculo acontece mediante o investimento afetivo e a sensibilidade materna para responder aos sinais e comunicações infantis.

Contudo, as mães têm maneiras diferentes de interagir e de se ligar emocionalmente aos filhos, portanto, o vínculo estabelecido com o bebê sofre influência das variações da sensibilidade materna. Mães sensíveis, que conseguem responder aos sinais e comunicações do bebê, tendem a oportunizar uma segurança emocional e exploratória aos filhos. Já mães emocionalmente distantes ou insensíveis poderão rejeitar as manifestações da criança, demonstrando irritação e impaciência na interação com ela. Inclusive, essas mães tendem a demonstrar maior dificuldade em manter proximidade corporal com seus bebês (Ainsworth, 1982). Assim, a repetição do padrão das interações iniciais entre a mãe (ou cuidador substituto) e o bebê formará um modelo interno com o qual a criança irá estabelecer as suas futuras relações (Bowlby, 1969/2002).

A presença de cuidados disponíveis e contingentes é essencial para a formação de um apego seguro (Bowlby, 1969/2002, 1976/2006) pelo bebê. Desse modo, a sensibilidade e a responsividade do cuidador têm relação estreita

1 Endereço para correspondência: Centro de Ciências da Saúde, Campus Unisinos, São Leopoldo, RS, CEP. 93.022-000.

E-mail: gabrielagolin@terra.com.br com a Teoria do Apego (Piccinini, Alvarenga, \& Frizzo, 2007; Ribas \& Moura, 2004), além de se aproximarem dos conceitos de preocupação materna primária e de mãe suficientemente boa postulados por Winnicott (Wendland, 2001). Ambas as teorias mencionam como imprescindível à criança pequena a sintonia afetiva entre ela e a mãe (ou um cuidador substituto) para a aquisição do sentimento de segurança emocional.

Entretanto, eventos traumáticos na infância, como perdas precoces ou a institucionalização, poderão alterar o padrão de apego estabelecido até então, pela criança (Ainsworth, 1982; Robertson, 1953). Na Romênia, Smyke, Dumitrescu e Zeanah (2002) compararam três grupos de crianças a fim de determinar se a presença de sinais de transtornos do comportamento de apego era maior em crianças institucionalizadas. O primeiro grupo foi composto por 32 crianças institucionalizadas, o segundo, por 29 em uma unidade-piloto projetada para reduzir o impacto da institucionalização e o terceiro, por 33 crianças residindo em suas casas, que nunca haviam sido institucionalizadas. Os pesquisadores concluíram que o desenvolvimento emocional de crianças institucionalizadas deve ser estimulado por meio da formação de relações de apego seletivo, mesmo em ambientes institucionais. Dessa forma, segundo eles, existe uma possibilidade de se diminuir o impacto da exposição a inúmeros cuidadores e, no caso de futura adoção, de permitir condições mínimas para o desenvolvimento de vínculos afetivos mais estáveis (Smyke et al., 2002). 
Face a isso, a partir da literatura, verifica-se que crianças cujas vivências primárias foram inapropriadas e abusivas, tendem a ficar extremamente inseguras e com dificuldades relacionais devido a tais experiências ameaçadoras (Gauthier, Fortin, \& Jéliu, 2004; Howe, 2003; Main \& Hesse, 1990; Rygaard, 2008; Winnicott, 1984/2002). Elas podem impactar cuidadores substitutos com o seu imenso sofrimento, intensa revolta e perturbação emocional, acionados por meio dessa nova interação (Howe, 2003; Rygaard, 2008; Winnicott, 1984/2002). Considerando-se esses aspectos, este estudo teve como objetivo a análise das demandas psicológicas de três crianças abrigadas, observadas a partir da sua interação com seus cuidadores no ambiente do abrigo.

\section{Método}

\section{Participantes}

Participaram deste estudo três meninos abrigados, com idades entre 1 e 2 anos e seus respectivos cuidadores. Os meninos residiam há pelo menos seis meses em uma instituição de acolhimento, localizada no estado do Rio Grande do Sul. Esta atende crianças de 0 a 12 anos encaminhadas pelo Conselho Tutelar e pelo Juizado da Infância. As crianças que participaram deste estudo foram selecionadas por conveniência.

\section{Procedimentos}

A instituição foi escolhida devido à disponibilidade de crianças pequenas. Em um primeiro momento, foram realizadas três reuniões com a equipe responsável, objetivando a autorização para a realização do estudo. Na terceira reunião, na qual participaram a psicóloga da instituição, além da professora orientadora desse projeto e a mestranda, foi entregue um Termo de Compromisso, contendo os objetivos do estudo e o pedido de autorização para a sua realização. Nesse sentido, o projeto foi avaliado e aprovado pelo Comitê de Ética em Pesquisa da UNISINOS, de acordo com a resolução 015/2009, protocolado sob o número 09/019, respeitando-se todas as normas da Resolução 196/96 do Ministério da Saúde.

A coleta de dados incluiu a realização de um estudo- piloto $^{2}$ que teve a duração de um mês, momento em que foi aplicada a Entrevista de Transtorno no Apego (Smyke \& Zeanah, 1999) nos cuidadores. Contudo, neste artigo, foram utilizados somente os dados de três participantes. Para a etapa de observação dos três casos selecionados, optou-se pelo Método Bick de Observação (inspiração no método), como técnica de coleta de dados. Assim, cada criança foi observada pela pesquisadora durante um mês, semanalmente, em

2 Tal avaliação oportunizou a avaliação do grupo de 23 crianças abrigadas quanto ao seu padrão de apego, através da aplicação da Entrevista de Transtorno de Apego (Smyke \& Zeanah, 1999). Para tanto, foram realizados oito encontros com os cuidadores (sempre em grupos de no máximo três participantes), respeitando-se a sua disponibilidade e os seus horários de trabalho e intervalos, com vistas a não prejudicar o cuidado das crianças. diferentes horários, porém respeitando-se o período de uma hora, com o intuito de conhecer a rotina e o ambiente como um todo, ou seja, o dia a dia das crianças observadas. Dentro disso, conforme o Método Bick (1964/2002) orienta, durante as observações não houve um foco pré-estabelecido, sendo que, ao final, essas foram relatadas na íntegra. A pesquisadora já havia feito tal formação e, para a realização do estudo, contou com a supervisão individual de uma psicanalista, especialista no método. Os dados da história de vida das crianças foram obtidos junto à equipe técnica da instituição pela documentação existente no local e, também a partir da fala informal de cuidadores e da própria equipe diretiva.

\section{Instrumentos e Procedimentos}

Os instrumentos utilizados no estudo foram: a) Entrevista de Transtorno no Apego (Smyke \& Zeanah, 1999): Trata-se de uma entrevista semi-estruturada, que deve ser respondida por cuidadores que conhecem bem a criança e seu comportamento. A entrevista é composta por 12 itens referentes a uma série de questões probatórias do comportamento infantil em relação aos cuidadores, que avalia a presença de "sinais comportamentais de transtornos de apego"; b) Método Bick de Observação (ORMB): Esse método foi concebido por Esther Bick, em 1948, que percebeu que psicoterapeutas de crianças poderiam se beneficiar em seu trabalho clínico, aprendendo a observar a criança e sua família (Bick, 1964/2002). Neste estudo, a observação aconteceu em uma instituição de abrigo, tendo em vista o contexto do estudo. Assim, foi realizada uma inspiração no método. Entretanto, seguiram-se os seus princípios básicos: a observação, o relato das observações e a supervisão dos casos relatados (Bick, 1964/2002); c) Dados da história das crianças: Esses dados foram obtidos por meio da documentação existente no local, a partir da fala informal de cuidadores e da própria equipe diretiva. Foram utilizados para enriquecer a compreensão da história de vida das crianças observadas, bem como os motivos que as levaram à institucionalização e, d) Entrevista não estruturada: A entrevista não estruturada permite maior riqueza e flexibilidade na coleta dos dados, constituindo-se como mais um recurso para se acessar as demandas psicológicas dos cuidadores e a sua percepção das crianças observadas. Ao todo, foram feitas duas entrevistas com os cuidadores principais das crianças observadas, ou seja, somente $\mathrm{C} 1 \mathrm{e}$ C6 participaram dessa etapa, tendo-se em vista o critério de que o cuidador deveria conviver com as crianças observadas, sendo responsável pelos seus cuidados pelo período mínimo de seis meses. As entrevistas foram gravadas em áudio e posteriormente transcritas.

Para a integração e análise dos dados, foi utilizada a estratégia analítica geral de descrição de caso proposta por Yin (2005). Na primeira etapa, foi realizada a descrição abrangente de cada caso por meio da organização dos dados, que incluiu: a) as características e comportamento de apego de cada criança, avaliados por meio da Entrevista de Transtorno de Apego (Smyke \& Zeanah, 1999); b) a síntese das observações de cada caso, organizada a partir das categorias: o ambiente cuidador, interação criança-cuidadores e impressões e impacto emocional da pesquisadora; $\mathrm{c}$ ) dados 
da história de vida das crianças observadas e, d) entrevista não estruturada com os cuidadores.

Em seguida, na segunda etapa, foi utilizada a técnica analítica de construção da explanação, cujo objetivo é analisar os dados de cada caso a partir de uma explanação psicodinâmica sobre eles. Na etapa seguinte, utilizamos a técnica de Síntese de Casos Cruzados. Assim, na discussão dos dados, buscou-se analisar as demandas psicológicas das crianças observadas, com base na interação criança-cuidadores investigada nesse contexto.

\section{Resultados e Discussão dos Casos}

Trata-se de uma instituição municipal do estado do RS que, no momento da pesquisa, abrigava 23 crianças com idades entre 0 e 12 anos. O abrigo é todo cercado por grades, tem um pequeno pátio na frente da casa e um espaço maior nos fundos. É uma casa de dois andares, bem conservada, organizada, limpa e espaçosa. O quadro geral de funcionários é composto por 22 pessoas, destas, cinco são estagiárias (geralmente são alunas do curso de Pedagogia), nove cuidadores concursados, uma coordenadora, que exerce a função da Diretora da casa. As outras pessoas se dividem entre a cozinha e o serviço geral. Além disso, a instituição conta com o apoio de uma equipe técnica, que é formada por uma psicóloga, uma assistente social e uma pedagoga.

\section{Caso I ${ }^{3}$ : Maurício, um 1 e 5 meses...}

Maurício vivenciou o acolhimento quando contava com 10 meses de idade. De acordo as informações obtidas, sua mãe é usuária de drogas e o seu pai foi preso. Além disso, conforme o depoimento da vizinha (que se sentiu responsável por ele e por sua irmã de 4 anos), durante as ausências maternas, as crianças eram deixadas sozinhas em casa, situação essa frequente, que levou ao seu acolhimento.

Esse quadro torna-se ainda mais perturbador diante da ruptura vivenciada por Maurício, que nunca recebeu visitas da mãe durante a institucionalização. Os cuidadores relataram que Maurício é uma criança carinhosa, entretanto, bastante irritada, principalmente quando frustrado:

Olha, eu achava o Maurício uma criança assim, bastante carinhosa, ele, se tava sentada ele te procurava pra fazer um carinho e tal. Achava ele bastante carinhoso, mas ele era muito dificil de lidar assim, questão de ter que dividir alguma coisa com alguém, ele era uma criança muito irritada $(\mathrm{C} 1$ - Cuidadora de Maurício).

Conforme Winnicott (1979/2007), quando a criança não tem um ambiente facilitador em função de uma falha no holding inicial, existe uma quebra na continuidade do ser. Nesse sentido, a irritação de Maurício, citada por C1, pode ser associada a uma falha na continuidade mãe-bebê, que tende a gerar uma sobrecarrega para a criança, que não pode relaxar pelo excesso de estímulos ou intrusões ambientais,

3 Os nomes são fictícios para preservar a identidade dos participantes. já que ela não se sente segura e naturalmente atendida em suas necessidades.

Estando no ambiente institucional, Maurício recebeu cuidados múltiplos. Durante as observações, ele buscava por qualquer cuidador quando necessitava ou queria atenção. Às vezes, tinha retorno, já em outros momentos, ele próprio acabava se consolando, parecendo estar adaptado ao contexto institucional. Robertson (1953) classificou como: protesto, desespero e desapego, as fases que levam a criança a se adaptar ao novo ambiente. Ou seja, ela passa a aceitar cuidados indiscriminados, ao mesmo tempo em que se desliga afetivamente da figura materna, situação que acontece após a vivência de um doloroso luto.

Nesse sentido, de acordo com Bowlby (1969/2002), os comportamentos de apego são manifestados quando a criança necessita de cuidados ou de conforto, sendo utilizados como estratégias para se atingir a meta fixa de aproximação física com a figura de apego. Nesse sentido, Maurício chorou, estendeu os seus braços na direção dos cuidadores, balbuciou alto para eles, sempre buscando contato e atenção.

No resultado da Entrevista de Transtorno no Apego, Maurício apresentou o padrão Não Apego/Desinibição, que corresponde às crianças sem figura de apego específica, mas que se mostram mais independentes e capazes de alguma resposta emocional recíproca, apesar do alto nível de comportamento indiscriminado. Assim, durante as observações, Maurício mostrou-se bastante expressivo e ativo, parecendo ter mais idade. Geralmente independente, circulava pelo ambiente parecendo sempre saber o que queria: buscou segurar-se na mão de $\mathrm{C} 1$, em outros momentos estendeu os braços para ela, solicitando-a por meio de uma linguagem pré-verbal, sendo atendido por $\mathrm{C} 1$ na maior parte das vezes.

Entretanto, em alguns momentos, durante as observações, Maurício ficou por longos períodos no berço. Nesses momentos, ele balbuciou alto para os cuidadores (qualquer um) chamando-os, jogou a coberta e travesseiro para fora do berço, estendeu os braços, chorou, sem buscar por alguém específico. Nessas situações, depois de um tempo, ele parecia desistir de ser atendido, desviando a atenção para a televisão ou para o seu próprio corpo.

Winnicott (1971/1975) refere que o olhar da mãe é o espelho da criança. Mas, e quando esse espelho é falho e não reflete a imagem da criança? Nesses casos, conforme Winnicott (1971/1975), a criança é a mãe. Ou seja, ela precisa aprender a decifrar a mãe e seus estados emocionais para poder sobreviver, utilizando-se da intelectualização.

Nesse viés, no caso de Maurício, supõe-se que a inconstância do comportamento materno (mãe dependente química) levaram-no a "estudar" precocemente o ambiente, que não lhe proporcionou segurança e estabilidade nesse processo. Será que Maurício precisou compensar intelectualmente a imprevisibilidade materna? Ele é um menino bastante inteligente e ativo, tanto que, durante as observações, mostrou-se competente em suas manifestações e desejos, destacando a sua capacidade de "se virar" e de se fazer entender.

Cabe mencionar que um tio materno de Maurício, que reside em outro Estado, juntamente com sua companheira, solicitou a sua guarda e da sua irmã, logo após as observações. Entretanto, Maurício foi devolvido pelo tio por ser uma criança difícil. Nesse sentido, C1 também apontou que, “em 
alguns momentos, Maurício é um menino brabo" (sic), com o temperamento forte.

De fato, isso reforça a reflexão de que crianças que vivenciaram múltiplas situações traumáticas na primeira infância, evidenciadas pelo abandono, pela carência contínua de afeto e de atenção, além das que sofreram experiências de abuso e negligência por parte da família em idade precoce, geralmente exigem muito do ambiente (Howe, 2003; Rygaard, 2008; Winnicott, 1984/2002). Ou seja, devido a um modelo de apego conflitante e ameaçador vivenciado inicialmente a partir do padrão de interação estabelecido com os cuidadores primários (Fonagy, 2000; Gauthier et al.., 2004; Howe, 2003; Rygaard, 2008), se torna importante o amparo psicológico constante com os seus cuidadores institucionais ou pais adotivos (Rygaard, 2008; Winnicott, 1984/2002), já que a tendência é que a criança torne a repetir esse padrão de interação conflitante e perturbador com os cuidadores substitutos (Howe, 2003; Rygaard, 2008).

Além disso, sintomas como a tosse constante de Maurício, a sua voz rouca, a sua irritação e algum tipo de alergia corporal, estiveram sempre presentes nas observações, assim como a sua busca incessante por contato com os cuidadores. Supõe-se que esses comportamentos sinalizaram a sua demanda psicológica, evidenciando o seu desamparo, o seu sofrimento e a sua necessidade de cuidados constantes e disponíveis.

Diante disso, pelos dados obtidos, Maurício não parece ter contado com um ambiente institucional capaz de lhe proporcionar o desenvolvimento de um vínculo por meio de interações próximas e previsíveis, já que as interações aconteceram na maior parte do tempo de forma superficial, na maior parte das vezes, apressadamente, tendo em vista o número de bebês e a sua demanda. Portanto, constata-se que o ambiente não respondeu de forma constante e sensível às manifestações de Maurício.

\section{Caso II: Miguel, 1 ano de vida...}

Conforme os documentos sobre a história de Miguel, o primeiro acolhimento aconteceu aos 2 meses, portanto, este é o seu segundo acolhimento, ocorrido quando ele contava com 4 meses de vida. Ele estava muito doente, com sérios problemas respiratórios. A mãe não o levava ao médico e, diante disso, houve denúncia de negligência por parte de terceiros. Dessa forma, está sendo determinada a destituição do poder familiar devido à dificuldade materna em estabelecer um vínculo consistente com a criança.

Os cuidadores consideram Miguel como um menino meigo e com a saúde bastante frágil, além de refletirem preocupação com o seu desenvolvimento, mais especificamente, com o seu atraso motor. Diante disso, Miguel aparenta ser um menino quieto, contido, que parece estar bloqueado em seu desenvolvimento. Segundo C1: ...uma febrezinha, ele se amolece, fica todo mole, tu pega ele no colo, parece realmente um saquinho de batata que tu tá pegando, porque ele é todo molengo, ele se atira! Sabe, alguma coisa que abala, ele se desestrutura muito, muito fácil!

$\mathrm{C} 1$ relacionou a instabilidade emocional de Miguel com a sua situação familiar. Conforme C1, a mãe de Miguel não visita o filho há bastante tempo. A cuidadora percebe-a bastante desestruturada, inconstante: ela foi mãe adolescente, não éo primeiro filho, a gente percebe que ela acaba passando essa coisa de inconstância, dela não ter estrutura pra cuidar dele e isso acaba passando pra ele...

De acordo com Winnicott (1979/2007), na fase da dependência absoluta o bebê se encontra fusionado e totalmente dependente da mãe. Esse estado de dependência inicial perdura, aproximadamente, durante os seis meses iniciais de vida da criança. Miguel contava com 4 meses no seu segundo acolhimento. Portanto, no caso dele concluiu-se que é um menino que foi pouco investido, apesar das tentativas maternas de cuidar e de se ligar ao filho.

Com relação ao resultado da Entrevista de Transtorno no Apego, Miguel apresentou o padrão Não apego/Inibição, correspondente às crianças que parecem não ser apegadas a um cuidador específico, mostrando-se inibidas. Entretanto, reagem emocionalmente de forma positiva ao aconchego. Concomitantemente, encontrou-se o padrão Não Apego/ Desinibição, correspondente às crianças que também não têm uma figura de apego, mas, que parecem mais independentes e capazes de alguma resposta emocional recíproca, com alto nível de comportamento indiscriminado. Tal comportamento: inibição-desinibição converge com o comportamento de Miguel, passivo-ativo, doente-saudável, que foi observado e, ao mesmo tempo referido pelos seus cuidadores. Além disso, C2 comentou que uma cuidadora específica cuidou de Miguel de maneira especial e que ele reagiu a olhos vistos, mostrando-se mais ativo e feliz na sua presença.

Durante as observações, Miguel se esforçou para ser alimentado na hora do lanche ou quando buscou por algum brinquedo que lhe chamou a atenção. Ele também realizou algumas aproximações dos cuidadores, manifestando comportamentos de apego com eles (Bowlby, 1969/2002). Por exemplo, em uma observação, ele estava acordado em seu berço, em pé, olhando na direção dos cuidadores. Então, tirou o bico da boca jogando-o na direção de um cuidador, que pegou o bico e o devolveu. Miguel jogou novamente o bico, mas, dessa vez, ficou sem retorno. O cuidador lhe disse sorrindo: é meu! (referindo-se ao bico), ao mesmo tempo em que guardou o objeto no avental. Diante dessa situação, Miguel não reclamou, deitando-se novamente no berço...

Nesse sentido, o apego discriminado poderá se desenvolver mais facilmente quando o ambiente proporciona estímulos sociais, principalmente dos 6 meses ao primeiro ano de vida da criança (Bowlby, 1969/2002). Imagina-se que a interação ocorrida entre o cuidador especial (segundo C2) e Miguel tenha possibilitado a reação comportamental do menino. Todavia, sua demanda psicológica envolve cuidados mais constantes e consistentes, que possam lhe passar confiança e estímulos adequados, que respeitem e facilitem o seu desenvolvimento, reconhecendo o seu ritmo e o seu sofrimento.

Com suas pernas “molengas", soltas no andador, ele ficou bastante tempo parado, passivo diante das outras crianças que engatinhavam, caminhavam, conversavam, reclamavam... Para a pesquisadora, entrar em contato com o seu desamparo e com a sua dificuldade motora impactou-a tanto pela sua força como pelas tentativas de ir adiante. Assim como, Miguel a comoveu pelo seu extremo cansaço e pedidos por maiores cuidados: colo, proteção e afeto. 
Outro fator inquietante diante dessa análise refere-se aos comportamentos de apego, que segundo Bowlby (1969/2002), são: chorar, sorrir, aproximar-se e agarrar-se (à figura de apego), sugar e chamar pela mãe. Entretanto, será que o adoecimento de Miguel poderia ser pensado como tendo a função similar a de um comportamento de apego, diante de um padrão de interação patológico?

Ou seja, seria esse um padrão de busca de proteção e cuidado pelo ambiente institucional, uma vez que Miguel recebia cuidados diferenciados quando estava doente, mais próximos e responsivos, mantendo, desse modo, a atenção dos cuidadores? Ao mesmo tempo, com essa repetição, demonstra a sua necessidade de cuidados diferenciados e constantes.

Segundo Bowlby (1973/2004), o comportamento de apego pode ser ativado pelo cansaço ou pela doença, mas, e se a doença fosse um "comportamento de apego" ativado pelo desamparo institucional, sendo um último recurso dessas crianças por proteção, mesmo que indiscriminadamente?

\section{Caso III: Cristofer, 1 ano e 4 meses...}

Cristofer foi abrigado quando contava com 1 mês de vida, quando comprovada a sua adoção ilegal. Assim, não foi possível o contato com a mãe biológica desde o seu acolhimento. Além disso, não existem registros acerca de sua história. Somente teve-se acesso a informações acerca de sua história por meio do relato verbal da equipe. Sendo assim, imagina-se que Cristofer foi privado de um ambiente inicial tranquilo e favorável ao seu desenvolvimento. Devido a falhas ambientais, supõe-se que ele ficou impedido de se sentir seguro, já que a previsibilidade é o que possibilita o vir a ser contínuo (Winnicott, 1979/2007).

Como resultado da Entrevista de Transtorno de Apego, Cristofer apresentou o padrão Distorção na Base de Segurança. Nesse caso, as crianças mostram-se apegadas, porém, bastante confusas. Ou seja, a criança tem uma figura de apego preferida, entretanto, demonstra altos níveis de comportamento inibido e confuso, o que tende a tornar a relação com esse cuidador principal comprometida e perturbada.

Nesse sentido, C6 comentou que a cuidadora de um turno específico, a $\mathrm{C} 15$, é a preferida do menino, explicando que em seu turno de trabalho: "C15 dava maior atenção a Cristofer, brincava com ele e o atendia, cuidando-o de maneira diferenciada". Pode-se refletir que em seu turno de trabalho C15 manteve certa previsibilidade e constância na sua interação com esse menino. Além disso, C6 verbalizou que Cristofer buscava ficar próximo a ela, engatinhando atrás dela, resmungando para que ela o pegasse em seu colo. C6 referiu que Cristofer também age assim com ela própria. Nesse sentido, $\mathrm{C} 6$ e $\mathrm{C} 15$ podem ser consideradas suas $f i$ guras de apego, já que qualquer pessoa para qual se dirija o comportamento de apego se revela como uma referência para a criança (Bowlby, 1973/2004).

Em alguns momentos, principalmente no início das observações, a observadora não identificou o menino, que estava entre as crianças, e isso deixou-a incomodada. Inclusive, teve dificuldades para identificar o seu nome. Como ele tem um nome composto "Luis Cristofer", às vezes era chamado de Luis, e em outros momentos de Cristofer. Considera-se que isso aconteceu em função da indiscriminação vivida e sentida por ele, que não teve referências constantes e cuidados sensíveis aos seus sinais e à sua subjetividade. Quem é Cristofer? A falta de registros de sua história pode ser refletida a partir da falta de um nome, de uma identidade. Os próprios cuidadores não o chamavam pelo nome completo.

Conforme o relato de C6, Cristofer aceita ser confortado e responde reciprocamente a seus cuidadores preferidos: C6 e C15. Contudo, quando com pessoas não familiares, ele geralmente as observa, de forma séria e desconfiada e não costuma estender os braços na sua direção, como as crianças da instituição costumam fazer.

Os cuidadores o consideram um menino triste, deprimido. Diante disso, o fato de ter sido abrigado quando contava com 1 mês de vida, estando completamente vulnerável e impossibilitado de ter contato com a mãe biológica (adoção ilegal) pode ter contribuído para ele ter sido protegido, tanto por $\mathrm{C} 6$ como por $\mathrm{C} 15$.

Eu acho que esse que era um vínculo, eles tinham um vínculo bem forte, ela chegava, ele sempre ia atrás dela, ele não, como é que eu vou te dizer? Quando ela tava sentada no chão, ele não deixava que os outros se aproximassem muito dela, ele queria ela só pra ele. Então, ele ficava bastante tempo chamando a atenção dela, tipo, se ela dava o bico, ele atirava no chão pra ela ir buscar, ou ficava apontando os brinquedos, queria sempre a atenção dela e, quando ele via que os outros estavam chamando muita atenção, ele chorava (C1-Cuidadora de Cristofer, referindo-se à interação entre Cristofer e C15).

A preocupação materna primária (Winnicott, 1965/2001) é um estado regressivo e extremamente necessário para que a mãe se identifique com o seu bebê. Na fase da dependência absoluta, esse estado unitário entre mãe-bebê permite que a mãe reconheça as necessidades e comunicações infantis. Diante disso, o holding materno acontece mediante os cuidados físicos, maneira pela qual a mãe manifesta o seu amor ao bebê, protegendo-o, bem como levando em consideração a sua sensibilidade cutânea: tato, temperatura, sensibilidade auditiva, sensibilidade visual (Winnicott, 1979/2007).

Esses cuidados é que caracterizam a rotina e que possibilitam a vivência das experiências a partir do holding proporcionado pela mãe. Cristofer foi privado desse ambiente inicial constante, amoroso e previsível, já que foi manipulado e cuidado por diferentes cuidadores desde seu primeiro mês de vida no ambiente institucional.

C15 foi receptiva a Cristofer, afetiva e cuidadosa, quando, em uma observação específica ele chorou intensamente. Entretanto, na maior parte das observações, os cuidadores mostraram-se distantes afetivamente do menino. Por outro lado, ele também não é um bebê carismático e afetivo. Isso nos leva a pensar na demanda de Cristofer, que sinaliza a necessidade de cuidados estáveis, diferenciados e disponíveis.

Na situação de Cristofer, institucionalizado com 1 mês de vida, torna-se ainda mais necessária a compreensão do seu comportamento pelos cuidadores. Pode-se pensar que, no seu caso, tenha sido difícil aprender a se relacionar de maneira amorosa e clara. Múltiplos cuidados, manejos diferenciados e constantes rupturas com $\mathrm{C} 6$ e $\mathrm{C} 15$, podem ter reforçado o 
seu padrão de comportamento: confuso, perturbador e triste, sem saber o que fazer para ser aceito e atendido.

Portanto, apesar das dificuldades inerentes da realidade institucional, acredita-se que Cristofer desenvolveu o apego discriminado a partir de interações com C6 e C15, durante a sua estada nessa instituição de abrigo. Bowlby (1969/2002) refere que, tendo a oportunidade de desenvolver o apego discriminado entre os 6 meses e o seu primeiro ano, a criança tende a responder às interações sociais que o estimulem a fazê-lo. Cristofer parece ter se beneficiado pelo estabelecimento de interações sensíveis e receptivas, que proporcionaram o estímulo do seu desenvolvimento, embora os sinais de suas necessidades e intenso sofrimento transpareçam em sua expressão, sempre séria e triste.

Para finalizar, a pesquisadora foi informada de que Cristofer havia sido adotado! Atualmente, ele conta com 1 ano e 4 meses. Segundo Gauthier et al., (2004) e Wendland e Gaugue-Finot (2008), as crianças em situação de vulnerabilidade tendem a ser favorecidas quando têm a possibilidade de vivenciar interações constantes e seguras, de confiança durante a sua primeira infância. Diante disso, supõe-se que Cristofer poderá se beneficiar a partir de um ambiente constante, tendo pessoas mais atentas aos seus sinais e necessidades, a partir da sua adoção.

\section{Discussão Geral}

Com base nos casos analisados, constatou-se, como uma das demandas psicológicas das crianças observadas, a necessidade de maior constância nos cuidados, levando a um reconhecimento de sua individualidade. Esse dado converge com os encontrados em estudos clássicos e contemporâneos acerca do acolhimento precoce (Bowlby, 1976/2006; Burlingham \& Freud, 1954/1960; David \& Appell, 1964; Nogueira \& Costa, 2005; Parreira \& Justo, 2005; Robertson, 1953; Rygaard, 2008; Siqueira \& Andriatte, 2001; Smyke et al., 2002; Vectore \& Carvalho, 2008; Winnicott, 1984/2002), que enfatizam, na situação de ruptura com a família biológica, a necessidade de um contato receptivo e estável dessas crianças com um cuidador substituto, que possibilite o desenvolvimento do apego discriminado (Gauthier et al., 2004; Rygaard, 2008; Wendland \& Gaugue-Finot, 2008), de forma a amenizar os prejuízos causados pela privação materna e os traumas dela decorrentes (Rygaard, 2008; Smyke et al., 2002).

Tais vivências certamente foram refletidas nas manifestações comportamentais de apego identificadas nos três casos observados. Ainda que ativas na procura de uma figura de apego estável, contingente e sensível, as crianças neste estudo apresentaram distorções importantes no estabelecimento de vínculos, evidenciadas por comportamentos associados ao quadro de Transtorno de Apego. Conforme Rygaard (2008), crianças traumatizadas, abandonadas ou que não podem contar com cuidados afetivos e protetivos, poderão desenvolver o transtorno de apego reativo, devido a múltiplas situações de negligência a que são expostas repetidamente.

Outro dado importante deste estudo que se articula com a Teoria do Apego, foi a busca ativa das três crianças observadas pelos seus cuidadores. Além disso, quando não atendidas e reconhecidas em suas demandas, elas mostraram- -se angustiadas, assustadas e desligadas, ou seja, em alguns momentos, pareciam até mesmo desistir desse retorno. Essas situações aconteceram, principalmente, nas observações de Maurício e de Miguel, quando estavam nos berços, esperando para serem atendidos. Assim, após fazerem algumas tentativas de contato com os cuidadores (choravam, esticavam os braços, chamavam, sorriam e jogavam o bico na sua direção), notamos que eles passavam a se aquietar, olhando televisão e voltando-se para o seu próprio corpo.

Essa situação assemelha-se aos resultados do estudo de David e Appell (1964). Da mesma forma, essas autoras constataram que, a medida em que as crianças não eram correspondidas, sendo pouco percebidas em suas manifestações espontâneas, tais como sorrisos e balbucios, elas deixavam de fazer essas tentativas de aproximação em função da ausência de retorno ou resposta dos cuidadores.

Outro aspecto a ser considerado relaciona-se ao ambiente institucional. A casa onde fica o abrigo é espaçosa, limpa e clara. As crianças dispõem de vários brinquedos, tendo um espaço amplo para explorar, tanto em sua parte interna, como na parte externa. A equipe técnica que acompanha as crianças é bastante completa (diretora, psicóloga, assistente social, pedagogo) e, além disso, os profissionais verbalizaram a sua preocupação, o seu cuidado para que as crianças tenham cuidadores específicos nos três turnos, mostrando o seu real interesse com o seu bem-estar. Esse dado também vai em direção do resultado abordado por David e Appell (1964), que realizaram o seu estudo em uma instituição de referência quanto à organização externa. Assim, elas evidenciaram que a carência afetiva das crianças institucionalizadas é algo muito complexo, que vai além da preocupação dos profissionais, da organização e do visual da instituição.

Face a isso, Appell (1997) reforçou o fato de o ambiente do abrigo ser mais organizado, como um facilitador do trabalho com as crianças. Contudo, também salientou em seu estudo, que a maior necessidade nesse contexto é o amparo constante aos profissionais que se ocupam das crianças, para que eles não fiquem simplesmente se defendendo dos sentimentos acionados nas interações e para que possam trabalhar mais seguramente.

Isso também foi percebido no presente estudo, ou seja, o ambiente como um todo adequado e organizado, característica referida pelos cuidadores como algo positivo para as crianças. Entretanto, eles verbalizaram as dificuldades em lidar com os seus próprios sentimentos, o que reforça a sua necessidade de amparo psicológico e de supervisão em relação ao seu trabalho. Tendo maior clareza e entendimento dos afetos acionados durante as interações com as crianças, esses profissionais terão a possibilidade de estabelecer um holding com elas.

Nesse sentido, conforme informações obtidas com a equipe do abrigo, existem reuniões quinzenais com os cuidadores, quando são abordados os casos e situações diárias diversas. Esse dado diverge dos encontrados em outros estudos (Barros \& Fiamenghi Jr., 2007; Nogueira \& Costa, 2005; Vectore \& Carvalho, 2008), visto que os cuidadores dessa instituição têm um espaço para refletirem e contam com um acompanhamento sistemático do seu trabalho. Mesmo assim, tal espaço ainda parece ser insuficiente para lidarem com as questões que emergem da sua prática pro- 
fissional. Além disso, as demandas dos cuidadores também se referiram ao funcionamento institucional, não apenas aos aspectos emocionais.

De fato, os cuidadores verbalizaram a rotatividade de profissionais na instituição como uma condição de instabilidade que dificulta o seu trabalho e que parece prejudicar também as crianças. Essa situação é destacada no estudo de Parreira e Justo (2005), que refletem acerca da impossibilidade da manutenção dos vínculos nos abrigos, referindo separações constantes, inclusive entre as crianças, que ficam sem referências diante de tanto descaso.

Poder ou não poder se apegar... Até que ponto se envolver... O vínculo acontece, mas as crianças vão embora... Essas são algumas das questões abordadas pelos cuidadores que participaram deste estudo e que evidenciaram a necessidade de amparo psicológico para interagir com as crianças sob o seu cuidado de maneira mais próxima e viva. Tais questionamentos vão ao encontro de alguns trabalhos que retratam o paradoxo e o sofrimento vivenciado pelos cuidadores substitutos: o investimento afetivo é importante para as crianças abrigadas, entretanto, devem ter clareza de que este é o seu trabalho (Nogueira \& Costa, 2005; Wendland \& Gaugue-Finot, 2008).

\section{Considerações Finais}

Considerando os objetivos deste estudo, ou seja, a análise das demandas psicológicas de três crianças abrigadas e de seus cuidadores, foi possível perceber que, apesar das características diferenciadas, os bebês observados buscaram ativamente pelos cuidadores, evidenciando a sua demanda psicológica por cuidados disponíveis e protetivos. O seu desamparo frente à realidade institucional reflete a fragilidade vivenciada pela institucionalização; ao serem retirados das famílias, eles deveriam contar com cuidados sensíveis e estáveis, que atendessem as suas necessidades básicas e demandas afetivas.

Entretanto, a rotina dessas crianças é apressada, havendo poucas possibilidades de interações de qualidade, ou seja, de respostas aos seus sinais e necessidades. Diante disso, nota-se uma falha do ambiente institucional, que deveria possibilitar interações privilegiadas entre cuidadores substitutos e crianças abrigadas, principalmente, no que se refere ao favorecimento de interações constantes, seletivas, previsíveis e de confiança, oportunizando um novo modelo de apego a elas (Rygaard, 2008).

Os cuidadores, por sua vez, também manifestaram a demanda por um holding institucional, uma sustentação de seu trabalho, que promova condições de cuidados estáveis e que permita um envolvimento mais próximo e claro com as crianças. Além disso, verbalizaram a necessidade de maior amparo emocional para lidarem com os seus sentimentos e fantasias, acionados durante a interação com as crianças.

Portanto, os dados obtidos denunciam um ambiente falho e com poucas alternativas de interações de qualidade para os bebês. Logo, considera-se urgente a necessidade de estudos futuros que abordem intervenções específicas com os cuidadores, focadas no contexto institucional, principalmente em se tratando de crianças abrigadas precocemente.
Diante disso, por meio desse trabalho verificou-se que o vínculo entre cuidadores substitutos e crianças abrigadas acontece. Contudo, deve-se considerar que, muitas vezes, as crianças passam despercebidas e indiferenciadas nesse contexto. Assim, reforça-se a necessidade do favorecimento de um "vínculo institucional" pautado em "interações privilegiadas", ou seja, constantes e de confiança entre cuidadores substitutos e crianças abrigadas.

Para tanto, destaca-se a importância do psicólogo clínico, especialista nesse contexto, que poderá trabalhar com a equipe como um todo, de forma a ajudar na construção de um ambiente mais estável e previsível às crianças, a partir de um trabalho organizador com os cuidadores, favorecendo o estabelecimento de interações mais saudáveis, por meio de um holding institucional.

Em suma, estando na primeira infância, seja nos abrigos ou em famílias adotivas, essas crianças precisam contar com um ambiente seguro, previsível e estável, que as reconheça em suas necessidades e autonomia

\section{Referências}

Ainsworth, M. D. (1982). Attachment: retrospect and prospect. In C. M. Parkes, \& J. S. Hinde (Eds.), The place of attachment in human behavior (pp. 03-30). Nova York: Basic Books.

Appell, G. (1997). Que tipo de observação usar para acompanhar uma criança pequena em coletividade. In M. B. Lacroix, \& M. Monmayrant (Eds.), Os laços do encantamento: A observação de bebês, segundo Esther Bick, e suas aplicações (pp. 79-85). Porto Alegre: Artes Médicas.

Barros, R. C., \& Fiamenghi Jr., G. A. (2007). Interações afetivas de crianças abrigadas: Um estudo etnográfico. Ciência \& Saúde Coletiva, 12, 1267-1276.

Bick, E. (2002). Notes on infant observation in psychoanalytic training. In A. Briggs (Ed.), Surviving Space: papers on infant observation (pp. 37-54). Londres: Karnac. (Originalmente publicado em 1964)

Bowlby, J. (2002). Apego: A natureza do vínculo. São Paulo: Martins Fontes. (Originalmente publicado em 1969).

Bowlby, J. (2004). Separação: Angústia e raiva (vol. 2, Trilogia Apego e Perda). São Paulo: Martins Fontes. (Originalmente publicado em 1973)

Bowlby, J. (2006). Cuidados maternos e saúde mental ( $5^{\mathrm{a}}$ ed). São Paulo: Martins Fontes. (Originalmente publicado em 1976)

Burlingham, D., \& Freud, A. (1960). Meninos sem lar. Rio de Janeiro: Fundo de Cultura. (Originalmente publicado em 1954)

David, M., \& Appell, G. (1964). Etude des facteurs de carence affective dans une pouponnière. Psychiatrie de I'enfant, 4, 401-442.

Fonagy, P. (2000). Apegos patológicos y acción terapêutica. Revista de Psicoanálisis, 4, 1-12.

Gauthier, Y., Fortin, G., \& Jéliu, G. (2004). Applications cliniques de la théorie de l'attachement puor les enfants em famille d'accueil: Importance de la continuité. Médicine e Hygiène Devenir, 16, 109-139.

Howe, D. (2003). Attachment disorders: Disinhibited attachment behaviours and secure base distortions with special reference to adapted children. Attachment and Human Development, $5,265-270$. 
Main, M., \& Hesse, E. (1990). Parent's unresolved traumatic experiences are related to infant disorganized attachment status: Is frightened parental behavior the linking mechanism? In M. Greenberg, D. Cichetti, \& M. Cummings (Eds.), Attachment in the preschool years: Theory, research and intervention (pp. 161-182). Chicago: University Press.

Nogueira, P., \& Costa, L. F. (2005). Mãe Social: Profissão? Função materna? Estilos da Clínica, 10(9), 162-181.

Parreira, S. M. C. P., \& Justo, J. S. (2005). A criança abrigada: Considerações acerca do sentido da filiação. Revista Psicologia e Estudo, 10, 175-180.

Piccinini, C.A., Alvarenga, P., \& Frizzo, G. (2007). Responsividade como foco de análise da interação mãe-bebê e pai-bebê. In C. A. Piccinini \& M. L. Seidl de Moura (Eds.), Observando a interação pais-bebê-criança (pp.131-153). São Paulo: Casa do Psicólogo.

Ribas, A., \& Moura, M. (2004). Responsividade materna e teoria do apego: Uma discussão crítica do papel de estudos transculturais. Psicologia: Reflexão e Crítica, 17, 315-322.

Robertson, J. (1953). Some responses of young children to the loss of maternal care. Nursing Times, 18, 382-387.

Rygaard, N. P. (2008). El niño abandonado: Guía para el tratamiento de los transtornos del apego. Barcelona: Gedisa.

Siqueira, L. A., \& Andriatte, A. M. (2001). Um estudo observacional sobre o vínculo afetivo de bebês abrigados em instituições. Boletim de Iniciação Científica em Psicologia, 2, 08-25.

Smyke, A. T., \& Zeanah, C. H. (1999). Disturbances of attachment interview. New Orleans: Tulane University School of Medicine.

Smyke, A. T., Dumitrescu, A., \& Zeanah, C. H. (2002). Attachment disturbances in young children I: The continuum of caretaking causality. Journal of the American Academy of Child and Adolescent Psychiatry, 41, 972-982.
Vectore, C., \& Carvalho, C. (2008). Um olhar sobre o abrigamento: A importância dos vínculos em contexto de abrigo. Psicologia Escolar e Educacional, 12(2), 01-14.

Wendland, J. (2001). A abordagem clínica das interações pais-bebê: Perspectivas teóricas e metodológicas. Psicologia: Reflexão e Crítica, 14, 45-56.

Wendland, J., \& Gaugue-Finot, J. (2008). Le développement du sentiment d'affiliation des enfants placés en famille d'accueil pendant ou après leur petite enfance. Médicine et Hygiène, 20, 319-345.

Winnicott, D. (1975). O brincar e a realidade. Rio de Janeiro: Imago. (Originalmente publicado em 1971)

Winnicott, D. (2001). A família e o desenvolvimento individual. São Paulo: Martins Fontes. (Originalmente publicado em 1965)

Winnicott, D. (2002). Privação e Delinquência. São Paulo: Martins Fontes (Originalmente publicado em 1984)

Winnicott, D. (2007). O ambiente e os processos de maturação: Estudos sobre a teoria do desenvolvimento emocional. Porto Alegre: Artmed. (Originalmente publicado em 1979)

Yin, R. K. (2005). Estudo de caso: Planejamento e métodos ( $3^{\mathrm{a}}$ ed.). Porto Alegre: Bookman.

Recebido em 19.04.2010

Primeira decisão editorial em 08.05.2013

Versão final em 08.05.2013

Aceito em 08.05.2013 